\title{
Monocytoid B cell lymphoma: clinical and prognostic features of 21 patients
}

\author{
S B Cogliatti, K Lennert, M-L Hansmann, T L Zwingers
}

\begin{abstract}
Twenty one patients between 34 and 83 years of age with monocytoid $B$ cell $1 y m-$ phoma (MBCL) of the lymph node were studied. The histological picture characteristically showed broad strands of medium sized cells with irregularly shaped nuclei and a fairly broad rim of slightly basophilic cytoplasm. One case developed into a centroblastic polymorphic lymphoma. Bone marrow infiltration was documented in three cases and leukaemic conversion in one case of MBCL. Seven patients had enlarged spleens. Eight patients were in stage $I$, five in stage $\mathrm{II} / \mathrm{II}_{\mathrm{E}}$, two in stage $\mathrm{III}_{3}$ and six in stage IV at the time of diagnosis. Of 18 patients subsequently followed up, eight were in complete remission, two in partial remission, and three were undergoing treatment at completion of the study; five patients had died. Relapse occurred in nine patients and was a common feature of MBCL. The prognosis of MBCL was comparable with that of other low grade malignant lymphomas. Fourteen patients presented with primary nodal lymphoma. In seven patients with nodal MBCL, however, a concomitant low grade $B$ cell lymphoma of the mucosa-associated lymphoid tissue (MALT) was also found in the stomach $(n=4)$, nasopharynx $(n=1)$, salivary glands $(n=1)$ and thyroid gland $(n=1)$. Two of these cases developed into high grade lymphoma. These extra-nodal manifestations were found simultaneously with $\mathrm{MBCL}$ in five patients. In another two patients, however, these symptoms occurred in a later phase of the disease.

It is emphasised that adequate staging procedures must be carried out in any case of nodal MBCL to exclude underlying low grade $B$ cell lymphoma of the MALT.
\end{abstract}

Immature sinus histiocytes, ${ }^{1}$ also termed monocytoid cells, ${ }^{2}$ were first described by Lennert in 1959 as a characteristic feature of Piringer's lymphadenitis ${ }^{1}$ long before these cells were identified immunohistologically by four independent study groups $(1984 / 85)$ as B lymphocytes that show positive reactivity with monoclonal B cell antibodies. ${ }^{3-6}$ These cells, for which the term monocytoid $B$ cells has been accepted, have also been found in other reactive lymph node lesions, including, increasingly, lymphadenopathy associated with AIDS $^{78}$ and occasionally Hodgkin's disease. ${ }^{9}$ Despite thorough investigations of the lineage links between monocytoid B cells and other cell subsets, the exact position of monocytoid B cells in the B cell system is still unknown..$^{3-6-16}$

The first malignant lymphoma composed of monotypic monocytoid B cells was described by McGinn et al in $1985 .{ }^{17}$ To date 56 cases of monocytoid B cell lymphoma (MBCL) have been documented. ${ }^{17-26} \mathrm{MBCL}$ has been compared with other low grade lymphomas from a morphological, immunological, and clinical point of view. ${ }^{917-2022252728}$ Though compatible with hairy cell leukaemia (HCL) in many aspects, ${ }^{21}{ }^{27} \mathrm{MBCL}$ has been established as a novel B cell neoplasm with a well defined morphological pattern and a distinct phenotype. Due to its extreme rarity few clinical data are available. ${ }^{2325} 28$

The objective of the present study was to evaluate diagnostic, clinical, and especially prognostic features of patients with monocytoid B cell lymphoma.

\section{Methods}

Twenty one cases of nodal MBCL were drawn from the files of the Lymph Node Registry in Kiel (table 1). In seven cases an additional lymphoma was documented in the stomach $(\mathrm{n}=4)$, nasopharynx $(\mathrm{n}=1)$, salivary glands $(n=1)$, or thyroid gland $(\mathrm{n}=1)$ (table 2). The histological sections were re-examined. They had been fixed in 5$10 \%$ formaldehyde, embedded in paraffin wax, and routinely stained with Giemsa, haematoxylin and eosin, periodic acid Schiff and Gomori's silver impregnation. Additionally, the sections were dewaxed, rehydrated, digested in trypsin and immunostained using the peroxidase-antiperoxidase method. ${ }^{29}$ Follow up of 18 patients provided prognostic data (table 3). Three of the patients could not be evaluated in terms of survival because the diagnosis was too recent. Clinical information was acquired from questionnaires and clinical reports provided by clinicians and general practitioners. Actuarial survival was calculated by the life table method of Kaplan and Meier. ${ }^{30}$

\section{Results}

Low power magnification of slides of MBCL showed broad strands and sheets of tumour 
Table 1 Clinical data on MBCL $(n=21)$

\begin{tabular}{|c|c|c|c|c|c|}
\hline Case No & Age (years)/sex & Presenting symptoms & $\begin{array}{l}\text { Prediagnostic } \\
\text { history (months) }\end{array}$ & Stage & Extra-nodal disease \\
\hline 1 & $68 \mathrm{~F}$ & Cervical and supraclavicular lymphadenopathy & 4 & $\mathrm{II}_{2 \mathrm{E}} \mathrm{A}$ & \multirow{9}{*}{ Spleen ${ }^{\star}$} \\
\hline 2 & $72 \mathrm{M}$ & Cervical lymphadenopathy & 2 & IA & \\
\hline 3 & $55 \mathrm{~F}$ & Cervical lymphadenopathy & 2 & IA & \\
\hline 4 & $74 M$ & Inguinal lymphadenopathy & - & IA & \\
\hline 5 & $80 \mathrm{~F}$ & Cervical lymphadenopathy & 6 & IA & \\
\hline 6 & $80 \mathrm{M}$ & Submandibular lymphadenopathy & 6 & IA & \\
\hline 7 & $56 M$ & Cervical lymphadenopathy & 12 & III $_{s} B(C S)$ & \\
\hline 8 & $64 \mathrm{M}$ & Generalised lymphadenopathy & 24 & III,A(CS) & \\
\hline 9 & $53 \mathrm{~F}$ & Gastric ulcer & 12 & $\mathrm{II}_{1 \mathrm{E}} \mathrm{B}$ & \\
\hline 10 & $45 \mathrm{M}$ & Gastric ulcer & 18 & $\mathrm{II}_{1 \mathrm{E}} \mathrm{A}$ & \multirow{5}{*}{$\begin{array}{l}\text { Spleen, }{ }^{\star} \text { liver } \\
\text { Bone marrow, liver } \\
\text { Bone marrow }\end{array}$} \\
\hline 11 & $57 \mathrm{M}$ & Generalised lymphadenopathy & + & IVB & \\
\hline 12 & $59 \mathrm{~F}$ & Gastric ulcer & 48 & IVA & \\
\hline 13 & $34 \mathrm{M}$ & Generalised lymphadenopathy initial flu & 2 & IVB & \\
\hline 14 & $77 \mathrm{~F}$ & Progressive goiter & 48 & $\mathrm{II}_{1 \mathrm{E}} \mathrm{A}$ & \\
\hline 15 & $83 \mathrm{~F}$ & Generalised lymphadenopathy & 3 & IVA (CS) & \multirow{3}{*}{ Bone marrow } \\
\hline 16 & $42 \mathrm{M}$ & Generalised lymphadenopathy & 1 & IVB & \\
\hline 17 & $76 \mathrm{M}$ & $\begin{array}{l}\text { Inguinal lymphadenopathy } \\
\text { Swelling of buttock }\end{array}$ & 1 & IB & \\
\hline 18 & $69 \mathrm{~F}$ & Supraclavicular lymphadenopathy & 1 & IA & \multirow{4}{*}{ Liver } \\
\hline 19 & $46 M$ & $\begin{array}{l}\text { Generalised lymphadenopathy } \\
\text { Initial flu }\end{array}$ & 8 & IVA & \\
\hline 20 & $54 \mathrm{~F}$ & Cervical/submandibular lymphadenopathy & 6 & $\mathrm{II}_{2} \mathrm{~B}$ & \\
\hline 21 & $40 \mathrm{~F}$ & Cervical lymphadenopathy & - & IA & \\
\hline
\end{tabular}

*Disease verified at necropsy or at a later stage of disease.

+Not evaluable.

Table 2 Patients in whom extranodal lymphoma was found simultaneously ( $n=5$ ) with nodal $M B C L$ or in a later phase of disease ${ }^{\star}(n=2)$

\begin{tabular}{lll}
\hline Extranodal lymphoma & Case No & $n$ \\
\hline Stomach & Cases 5, 9, 10,12 & $3\left(+1^{\star}\right)$ \\
Nasopharynx & 1 & 1 \\
Salivary gland & 13 & $11^{\star}$ \\
Thyroid & 14 & 1 \\
Total & & 7 \\
\hline
\end{tabular}

cells, focally confined to enlarged sinuses (in situ lymphoma ${ }^{23}$ ), but most often affecting the adjoining pulp. The capsule was always infiltrated and the nodal architecture was effaced to varying degrees (fig 1). The presence of reactive looking germinal centres was a feature in 11 cases. In some cases the growth pattern was noticeably perifollicular: in two mesenteric lymph nodes the tumour had spread within the marginal zone of some germinal centres adjacent to the subcapsular sinus (figs $2 a$ and $b$ ). Silver impregnation showed an

Table 3 Follow up data on MBCL $(n=18)$

\begin{tabular}{|c|c|c|c|}
\hline Case No & $\begin{array}{l}\text { Follow up } \\
\text { (months) }\end{array}$ & Primary treatment & $\begin{array}{l}\text { Response (months) } \\
\text { relapse }+1-\end{array}$ \\
\hline $\begin{array}{l}1 \\
2 \\
3 \\
4 \\
5 \\
6 \\
7 \\
8\end{array}$ & $\begin{array}{l}54 \\
68 \\
66 \\
35 \\
13 \\
61 \\
49 \\
48\end{array}$ & $\begin{array}{l}\text { Neck dissection } \\
\text { EFR ( } 45 \mathrm{~Gy}) \\
\text { IFR } \\
\text { Lymph node excision } \\
\text { Lymph node excision } \\
\text { IFR }(36 \mathrm{~Gy}) \\
4 \times \mathrm{COP}, 3 \times \mathrm{ABVD} \\
9 \times \mathrm{CHOP} \\
\text { Abdominal radiotherapy }(30 \mathrm{~Gy})\end{array}$ & $\begin{array}{l}\text { CR } 4+ \\
\text { CR } 66- \\
\text { CR } 55+ \\
\text { CR } 23+ \\
\text { CR } 3+ \\
\text { CR } 60- \\
\text { CR } 36+ \\
\text { CR } 23+\end{array}$ \\
\hline $\begin{array}{r}9 \\
10 \\
11 \\
12 \\
13 \\
14 \\
15 \\
16 \\
17 \\
18\end{array}$ & $\begin{array}{r}36 \\
21 \\
3 \\
15 \\
13 \\
20 \\
10 \\
9 \\
6 \\
83\end{array}$ & $\begin{array}{l}\text { Gastrectomy } \\
\text { Gastrectomy, abdominal radiotherapy } \\
\text { Leukeran/Decortin } \\
\text { Gastrectomy, } 6 \text { × CHOP } \\
6 \times \text { COP } \\
\text { Strumectomy, EFR }(45 \mathrm{~Gy}) \\
10 \times \text { KNOSPE } \\
\text { Leukeran/Decortin } \\
\text { Local excision } \\
4 \times \text { KNOSPE }\end{array}$ & $\begin{array}{l}\text { CR 22+ } \\
\text { CR } 16- \\
\text { PR } \\
\text { CR } 1+ \\
\text { CR } 10+ \\
\text { CR 18- } \\
\text { PR } \\
\text { PR } \\
\text { CR 6- } \\
\text { CR 78- }\end{array}$ \\
\hline
\end{tabular}

ABVD-Adriamycin, bleomycin, vinblastin, Decarbazine.

CHOP-Cyclophosphamide, 14-Hydroxydaumide, Oncovin, prednisone.

COP-Cyclophosphamide, oncovin, prednisone.

COP-BLAM-Cyclophosphamide, vincristine, prednisone, bleomycin, adriamycin, procarbazine.

CR/PR - Complete/partial remission due to primary treatment.

IFR/EFR-Involved/extended field radiation.

KNOSPE-Chlorambucil, prednisone.

-Died during follow up. increase in high endothelial venules in the tumour infiltrates. Under high power magnification the cytological appearance of the tumour cells varied considerably. In general, the cells were medium sized and showed slightly or extremely irregular, roundish to reniform or indented nuclei, with one to three inconspicuous nucleoli and a fairly broad rim of slightly basophilic cytoplasm (fig 3 ). In a paragastric lymph node from one case the tumour had developed into a centroblastic polymorphic lymphoma at the time of diagnosis.

The monocytic B cells exhibited monoclonal surface immunoglobulins in 14 cases and cytoplasmic immunoglobulins, predominantly $\operatorname{IgM} / \kappa(n=7)$ in eight cases. Three of these cases exhibited plasmacytic differentiation with plasma cells of the same clone. In two other cases, however, monoclonality was evident only in plasma cells (table 4). Varying numbers of immunoblasts (from the same clone) were found intermingled with the monocytoid B cells. Infiltration of the pulp by plasmacytoid and plasma cells was occasionally a dominant feature of the tumour.

When they were localised in the stomach or nasopharynx (fig 4), the extra-nodal manifestations that were combined with nodal MBCL in seven patients showed the characteristic features of a low grade B cell lymphoma of the mucosa-associated lymphoid tissue (MALT) including lymphoepithetial lesions $(n=4)$ and reactive intratumoural germinal centres $(n=4)$. One case, however, had developed into a centroblastic polymorphic lymphoma in the stomach and one into an unclassified high grade lymphoma in the salivary glands.

Of a total of 21 patients, aged 34 to 83 years, 11 were male and 10 female. The age distribution curve showed peaks in the 6th and 8th decades (fig 5).

\section{HISTORY BEFORE DIAGNOSIS AND INITIAL} SYMPTOMS

In 17 patients the initial symptoms were peripheral lymphadenopathy, localised at one site $(\mathbf{n}=9)$, two sites $(\mathbf{n}=2)$, or generalised 


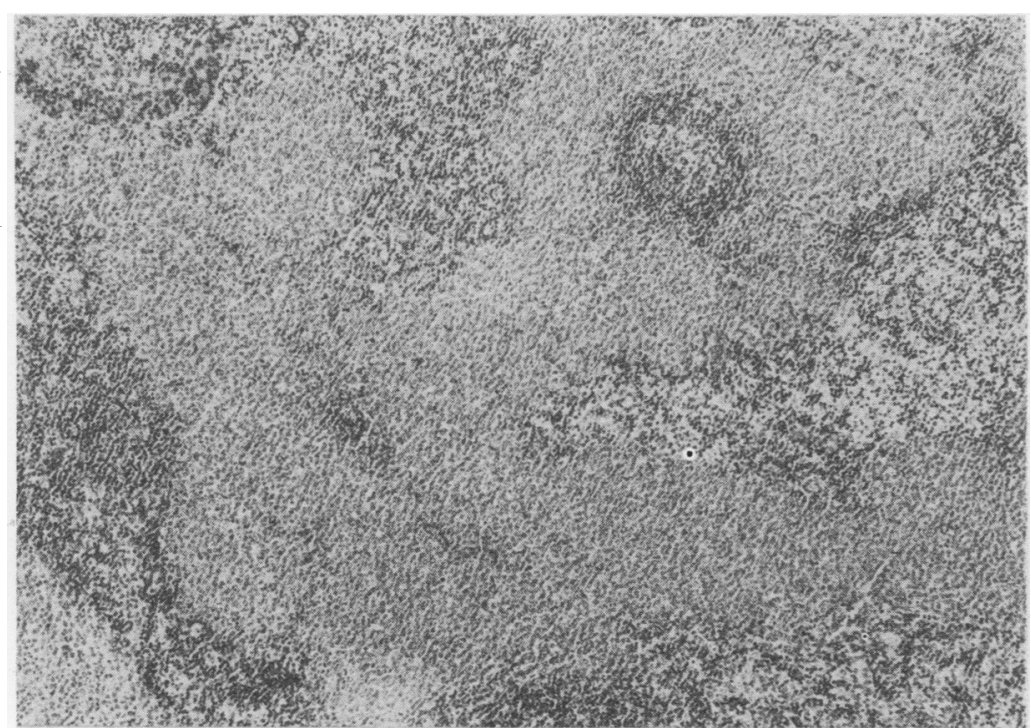

Figure 1 Lymph node infiltrated by $M B C L$ spreading in broad inter-and perifollicular strands. The tumour cells react weakly with monoclonal surface $\mu$ heavy chain

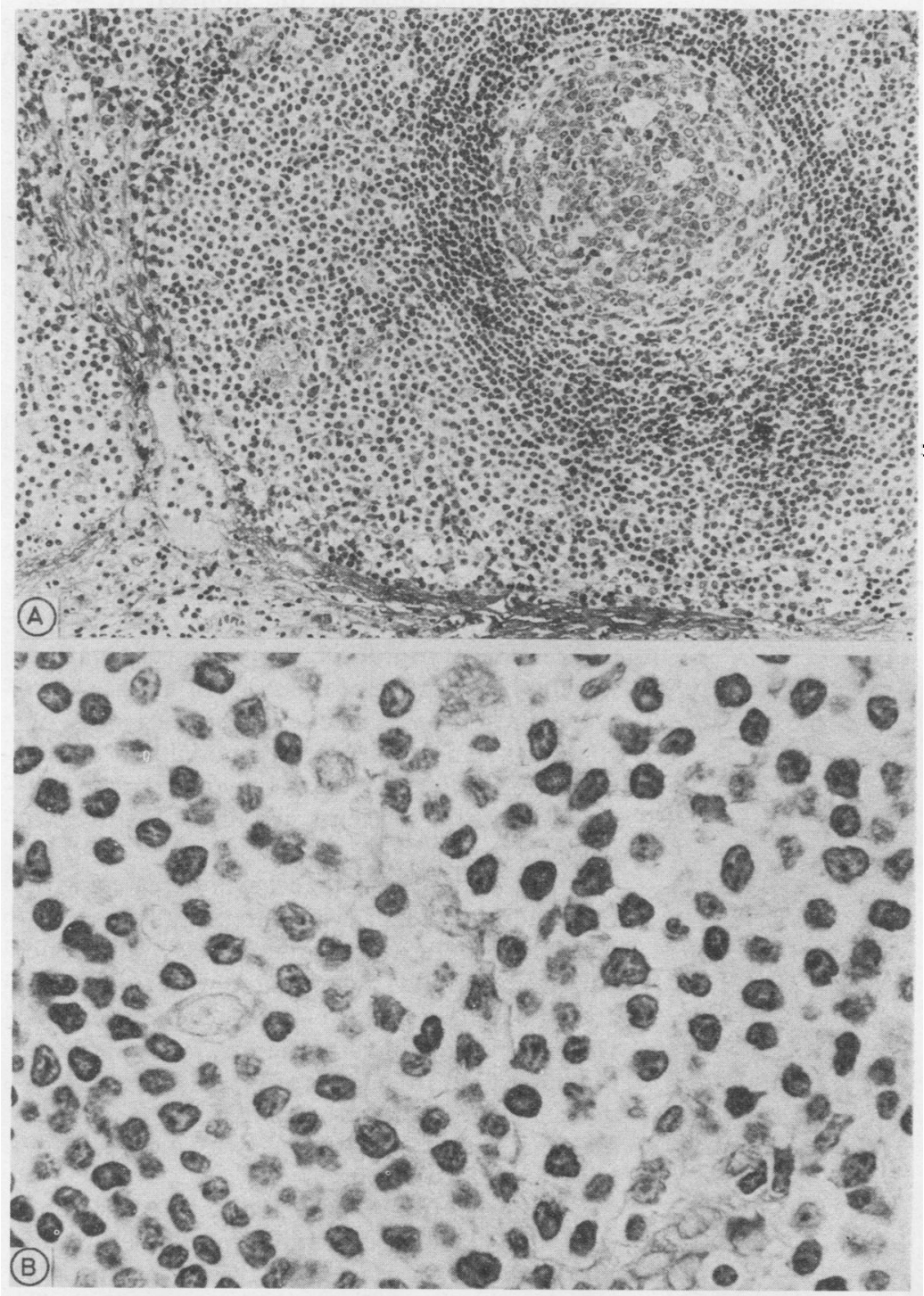

Figure 2 (A) Paragastric lymph node infiltrated by $M B C L$. A noticeably broadened marginal zone is clearly distinguishable from an inner mantle zone and a reactive germinal centre (Giemsa). (B) High power magnification of fig $2 a$ (Giemsa). $(n=6)$, lasting for between one month to two years. In one case a previous biopsy specimen of submandibular soft tissue had shown an undefinable lymphoid infiltration, and in another a previous submandibular swelling had shown spontaneous regression. Additional symptoms were flu-like episodes in two cases and swelling of the ipsilateral buttock in one case of inguinal lymphadenopathy. Three other patients with paragastric MBCL associated with gastric lymphoma had a history of persistent ulcers for one to four years. Finally, in one patient a history of progressing goitre over a period of four years and an earlier occurrence of Hashimoto's disease preceded an asymptomatic lymphoma in the thyroid combined with $\mathrm{MBCL}$ in a regional lymph node, both unexpectedly discovered in the thyroidectomy specimen.

Seven patients with MBCL initially had B symptoms. Fever was reported in three patients, night sweating in four, itching in one, and alcohol intolerance in two as well as weight loss in one patient with an additional gastric lymphoma.

ASSOCIATED DISEASES AND PREVIOUS AILMENTS

Nine patients also had minor or major cardiovascular disease. One patient presented with atopic trias and porphyria cutanea tarda due to liver cirrhosis and carcinoma, another with ethylic liver disease, and one with chronic persistent hepatitis. One patient had had benign colon polyps, three had tuberculosis, one had mononucleosis, and one had parotitis epidemica.

\section{LABORATORY FINDINGS}

An increased erythrocyte sedimentation rate (ESR) in six patients and anaemia in four were the most common, albeit unspecific, laboratory findings. Immunoelectrophoresis was performed on 12 patients showing a case of monoclonal IgG/ $\mathrm{k}$ gammopathy (case 19 ). Leukaemic conversion of MBCL was documented in case 16 who had a leucocytosis of $14 \times 10^{9} / 1$ with $80 \%$ medium sized lymphoid cells. In a mononuclear cell fraction from filtered, anticoagulated venous blood, medium sized cells with reniform or indented nuclei and abundant slightly basophilic cytoplasm were phenotypically identical with the tumour cells in the lymph node (fig 6).

\section{STAGING}

The initial stage of disease, according to the Ann Arbor classification, as modified by Musshoff, was determined by pathological or clinical staging methods, or a combination. Malignant pathology in lymph nodes and extranodal tissue was therefore histologically confirmed in 18 patients, but in cases 7,8 , and 15 it was presumed on the basis of findings from ultrasound scans, computed tomography, $x$-ray picture and palpation (clinical stage).

Eight $(38 \%)$ patients were in stage I. Cervical lymph nodes were affected in four of them, inguinal in two, submandibular in one, and supraclavicular lymph nodes in one. In 


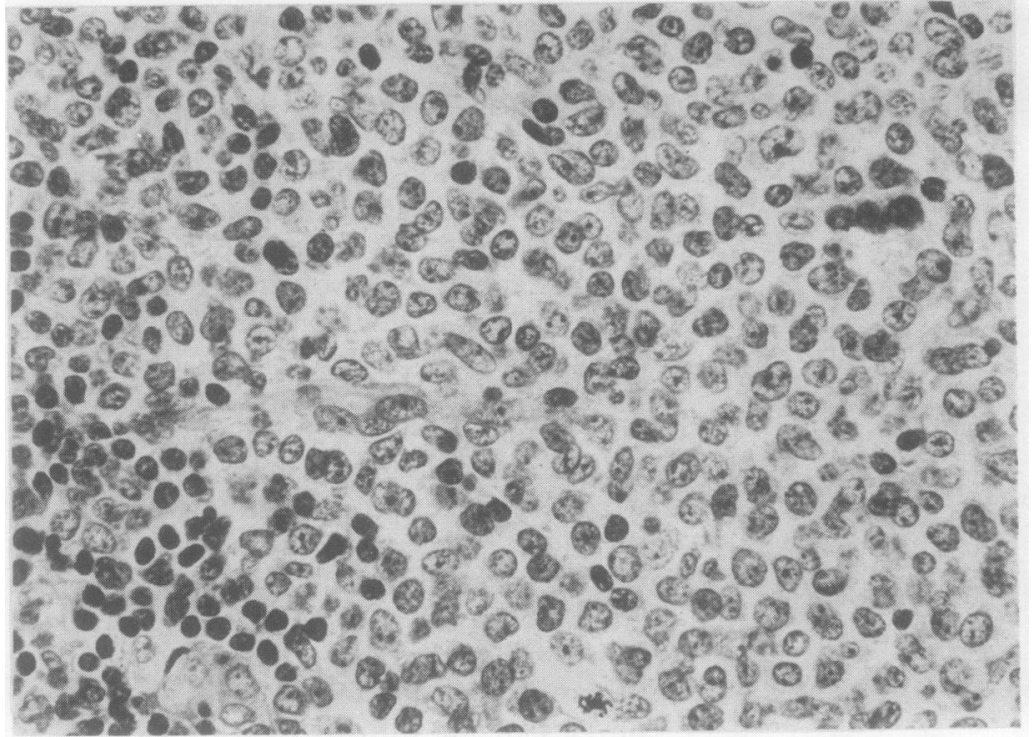

Figure $3 M B C L$ in the lymph node showing medium sized cells with irregularly shaped, indented nuclei and a broad rim of slightly basophilic cytoplasm (Giemsa).

Table 4 Immunophenotypes of tumour cells in $M B C L$ showing plasmacytic differentiation in five cases $(n=21)$

\begin{tabular}{|c|c|c|c|c|}
\hline \multirow[b]{2}{*}{ Case No } & \multirow[b]{2}{*}{ Immunophenotype } & \multicolumn{2}{|c|}{ Monocytoid B cells } & \multirow{2}{*}{$\begin{array}{l}\text { Plasma cells } \\
\text { cIg }\end{array}$} \\
\hline & & $s I g$ & $c I g$ & \\
\hline 1 & $\operatorname{IgM} / \kappa$ & + & + & + \\
\hline 2 & $\mathrm{IgM} / \kappa$ & + & + & - \\
\hline 3 & $\mathbf{I g M} / \lambda$ & + & + & - \\
\hline 4 & $\mathbf{I g M} / \kappa$ & + & - & - \\
\hline 5 & $\operatorname{IgG} / \kappa$ & - & - & ++ \\
\hline 6 & $\operatorname{IgM} / \kappa$ & + & $(+)$ & - \\
\hline 7 & $\operatorname{IgM} / \kappa$ & + & + & - \\
\hline 8 & $\mathrm{IgM} / \kappa$ & + & + & - \\
\hline 9 & $-/ \kappa$ & + & + & - \\
\hline 10 & $-/ \kappa$ & + & - & - \\
\hline 11 & $\operatorname{IgM} / \lambda$ & $(+)$ & - & - \\
\hline 12 & $\operatorname{IgM} / \lambda$ & + & - & - \\
\hline 13 & $? \star$ & - & - & - \\
\hline 14 & ?* & - & - & - \\
\hline 15 & $\operatorname{IgM} / \hat{\lambda}$ & + & + & + \\
\hline 16 & $\mathrm{IgM} / \kappa$ & - & - & + \\
\hline 17 & ?* & - & - & - \\
\hline 18 & ?* & - & - & - \\
\hline 19 & $\mathrm{IgG} / \kappa$ & + & - & + \\
\hline 20 & $-1 \lambda$ & $(+)$ & - & - \\
\hline 21 & $? \star \star$ & - & - & - \\
\hline
\end{tabular}

^Immunophenotypes not available.

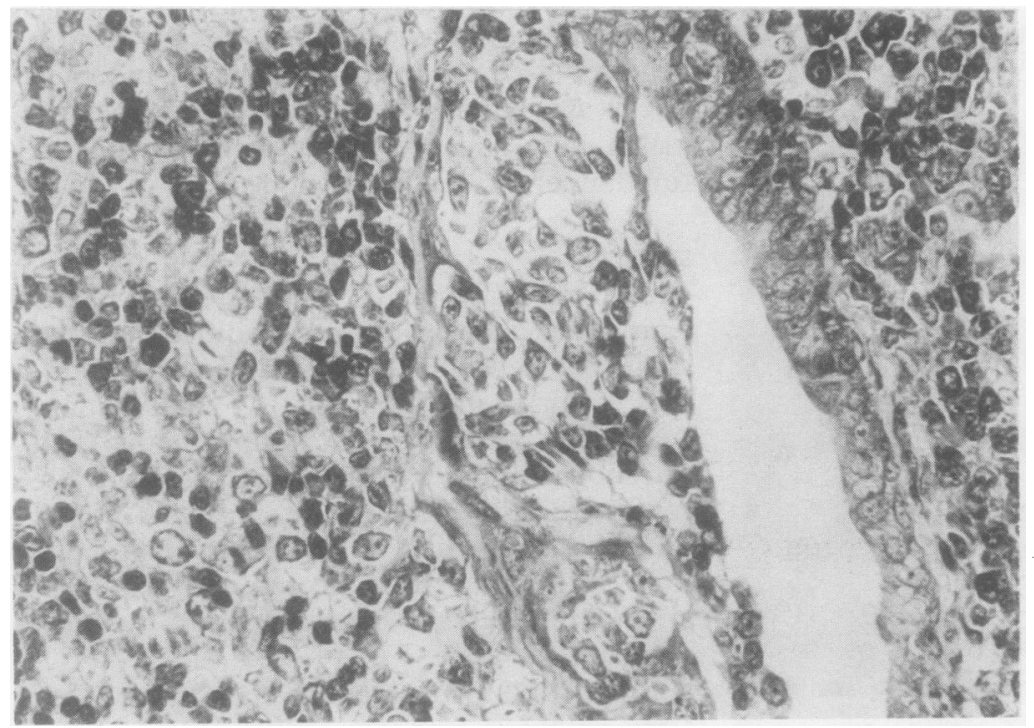

Figure 4 Lymphoepithelial lesion in a low grade B cell lymphoma of the MALT in the nasopharynx (Giemsa).

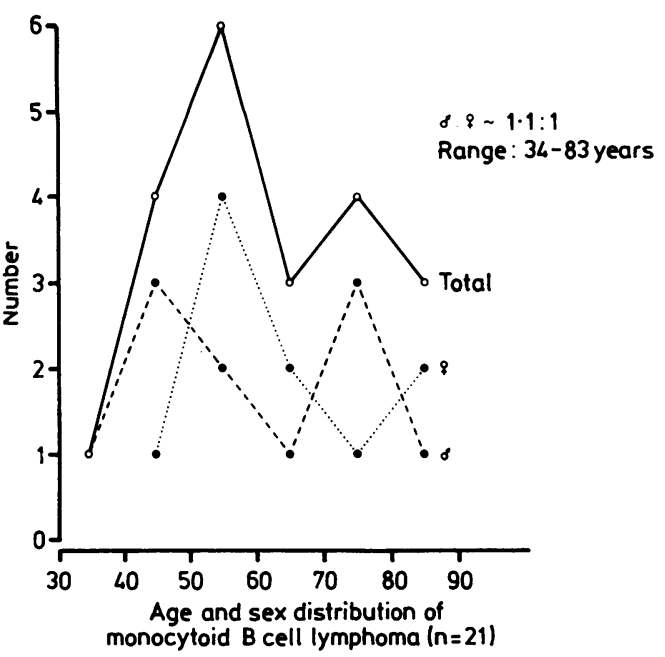

Figure 5 Age and sex distribution of monocytoid B cell lymphoma $(n=21)$.

case 5, however, who had cervical MBCL, a post mortem examination 13 months after diagnosis showed lymphoma in the stomach.

Five $(24 \%)$ patients were in stage $\mathrm{II} / \mathrm{II}_{\mathrm{E}}$. In one of them submandibular and cervical lymph nodes were affected. In four others with coincidental lymphomas in the stomach $(\mathbf{n}=2)$, nasopharynx $(n=1)$, and thyroid $(n=1)$ MBCL affected the corresponding regional lymph nodes.

Two patients in clinical stage $\mathrm{III}_{\mathrm{S}}(10 \%)$ had generalised or localised lymphadenopathy together with enlarged livers and spleens.

Six $(28 \%)$ patients were in stage IV. They had hepatosplenomegaly $(n=4)$, splenomegaly $(n=1)$, or hepatomegaly $(n=1)$ combined with generalised $(n=5)$ or localised $(n=1)$ lymphadenopathy. Pathological staging was performed in four patients with positive biopsy specimens of bone marrow $(n=2)$, liver $(n=1)$, or both $(n=1)$. In another patient spleen and liver disease were first confirmed during post mortem examination. In one case MBCL was combined with a lymphoma in the stomach and in one with a lymphoma in the salivary glands.

Treatment protocols for each case varied widely, irrespective of the stage of disease.

Diagnostic lymph node excision $(n=2)$ or complete removal of affected nodal and extranodal tissue $(n=3)$ was the only treatment given to three patients in stage $I$ and two patients in stage $\mathrm{II}_{\mathrm{E}}$.

Three patients in stage I were treated with radiotherapy alone; two patients in stage $\mathrm{II}_{\mathrm{E}}$ had radiotherapy postoperatively, and one patient in stage III $_{s}$ was treated with a combination of radiotherapy and chemotherapy. Different forms of radiotherapy were applied: involved field radiation (IFR) $(n=2)$, extended field radiation (ERF) $(n=2)$, or abdominal radiation $(n=2)$ with a dose ranging from 30 to $45 \mathrm{~Gy}$.

Chemotherapy alone was used to treat one patient in stage $\mathrm{I}$, one patient in stage $\mathrm{III}_{s}$, and four patients in stage IV. It was given as a supplement to gastrectomy in one patient in stage $I V_{E}$. The cytotoxic drugs were given most often as cycles of COP (cyclophosphamide, 


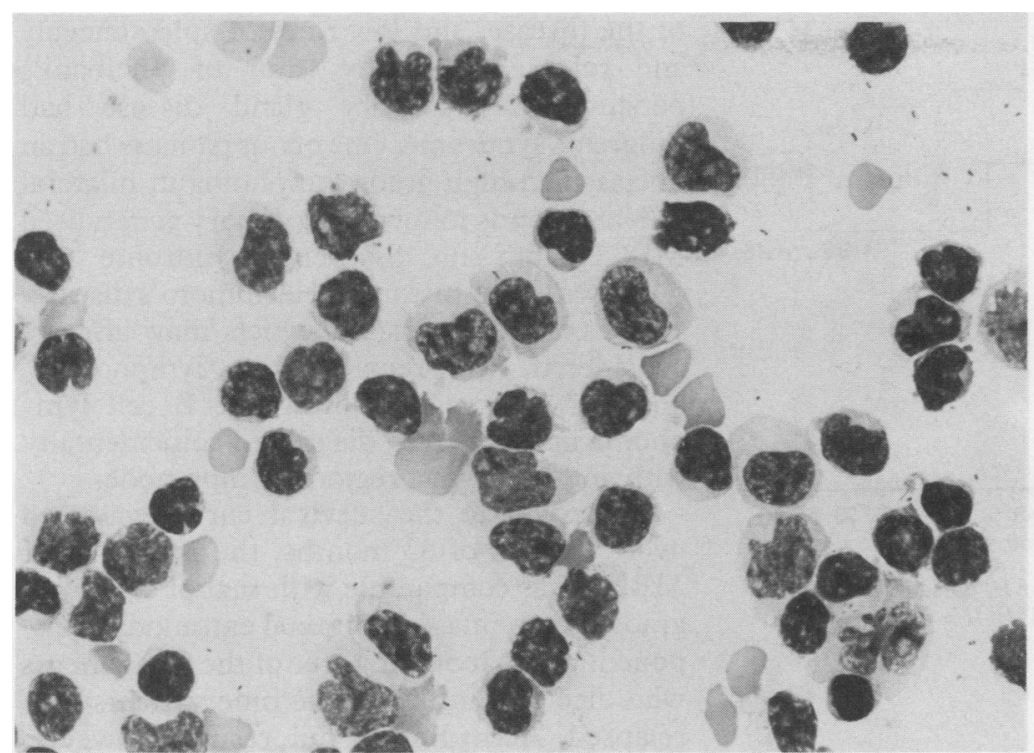

Figure 6 Mononuclear cell fraction from filtered, anticoagulated venous blood in a case of leukaemic MBCL. Medium sized cells show reniform or indented nuclei and a broad rim of slightly basophilic cytoplasm (May-Grünwald-Giemsa).

Oncovin, prednisone); CHOP (cyclophosphamide, 14-hydroxydaumide, Oncovin, prednisone) ABVD (adriamycin, bleomycin, vinblastin; decarbazine), and according to the KNOPSE scheme (chlorambucil, prednisone) and two patients received continuous Leukeran and Decortin.

\section{RESULTS OF TREATMENT}

Seven of the patients in stage I were followed up. They were all brought into complete remission, and four of them stayed free of relapse (maximum of 78 months). Case 2 with cervical lymphoma went into remission after EFR (45 Gy) and case 6 with submandibular lymphoma after IFR (36 Gy). In case 18 , with a supraclavicular manifestation, remission was achieved after four cycles of KNOSPE and in case 17, with inguinal lymphoma, after lymph node excision and complete removal of an undetermined infiltration in the ipsilateral buttock. Case 3, with cervical MBCL treated with IFR, had a relapse in an axillary lymph node after 55 months in remission. The lymph node was removed. No further evidence of lymphoma was found. Case 4, with inguinal MBCL, was not treated after diagnostic lymph node excision due to a myocardial infarction. Nodal and cerebral relapse occurred after 23 months and was treated with central nervous system radiation (50 Gy) and chemotherapy (COP), but the patient died 35 months after diagnosis. After one year case 5, who had recurrent cervical $\mathrm{MBCL}$, deteriorated rapidly with severe anaemia, diarrhoea, and ascites. She died soon after, following severe bleeding from a formerly ulcerated gastric lymphoma with peritoneal spreading and splenic disease.

The four patients in stage $\mathrm{II}_{\mathrm{E}}$ were followed up. They all went into comp!ete remission and two of them remained free of relapse. Case 10, who had shown malignant disease in the stomach and paragastric lymph nodes, went into remission after gastrectomy and abdominal radiation, and case 14 with manifest lymphoma in the thyroid and a regional lymph node, after strumectomy and EFR (45 Gy). Case 1, who had cervical and supraclavicular lymphadenopathy associated with nasopharyngeal lymphoma, experienced a local relapse four months after removal of the tumour and neck dissection. In spite of repeated surgery and radiotherapy the patient died 54 months after diagnosis in an unknown condition. Case 9, with gastric and paragastric disease, underwent gastrectomy. Local and para-aortal relapse after 22 months was treated with chemotherapy (COP) and abdominal radiation, and no further lymphoma was found.

The two patients in clinical stage $\mathrm{III}_{\mathrm{s}}$ were both brought into complete remission and both were followed up. Case 8 was treated with chemotherapy (CHOP) and abdominal radiation (30 Gy). After 23 months of complete remission a relapse occurred in the supradiaphragmatic lymph nodes accompanied by pleural effusion. Further chemotherapy (COPBLAM) resulted in only partial remission. Case 7, treated with chemotherapy (COP and ABV), had a relapse in cervical and axillary lymph nodes after 36 months of complete remission and was undergoing renewed chemotherapy (ABVD) at the completion of this study.

Five of the patients in stage IV were followed up and two of them went into complete remission. Case 12, who showed a coincidental gastric lymphoma and transformation into a centroblastic polymorphic lymphoma at gastric and paragastric sites, underwent gastrectomy and primary chemotherapy (CHOP). A generalised relapse occurred after one month of complete remission and the patient died before renewed radiotherapy had been fully administered, 15 months after diagnosis. In case 13 chemotherapy (COP) resulted in complete remission for 10 months, when an additional unclassified high grade lymphoma was discovered in bilateral salivary glands, just at the completion of this study. Three patients only were brought into partial remission: case 15 after 10 cycles of KNOSPE and cases 11 and 16, who were treated with continuous Leukeran or Decortin chemotherapy. Case 16 was still undergoing treatment at the completion of our study, but case 11 had died three months after diagnosis.

\section{PROGNOSIS}

Eighteen patients with MBCL were followed up for three to 83 months (mean follow up period 34 months). With treatment 15 patients were brought into complete remission for periods ranging from one to 78 months (mean 28 months). Six patients, all in early stages, stayed free of relapse (maximum 78 months). Nine $(50 \%)$ patients, however, relapsed after complete remissions lasting from one to 55 months (mean 20 months). Four were in an early stage and five in an advanced stage. In case 5 this was only discovered at necropsy. Only three patients managed to go into partial remission.

Five patients died within three to 54 months after diagnosis. Two of them were in an early stage and three in an advanced stage at diag- 


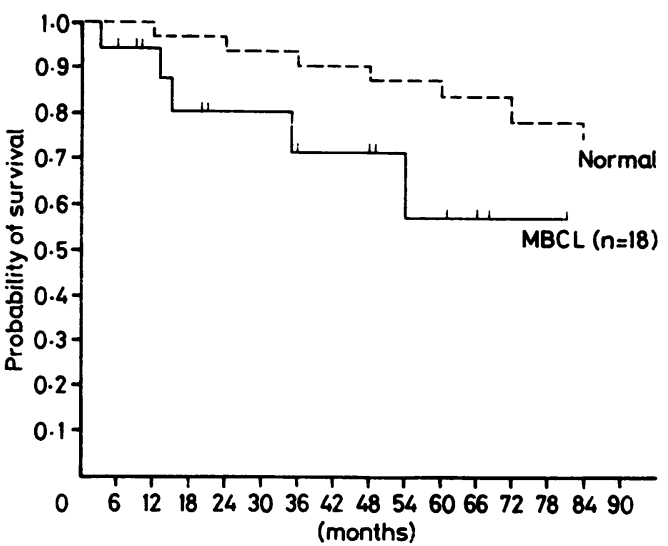

Figure 7 Actuarial survival of 18 patients with monocytoid $B$ cell lymphoma $(M B C L)$ in comparison with the normal population.

nosis. Patients in an advanced stage died within a much shorter time than those in an early stage.

When this study had been completed eight patients were in complete remission, two in partial remission, and three were undergoing treatment.

Overall, the probability of survival for the whole group after 83 months was lower than that for a comparable normal population. The survival curve showed a constant downward slope with no plateau (fig 7), comparable with the progression seen in other low grade lymphomas.

\section{Discussion}

Twenty one patients with MBCL were studied and 18 of them evaluated for prognostic features. Special emphasis was placed on seven cases in which the nodal MBCL occurred in combination with a lymphoma in the stomach $(n=4)$, nasopharynx $(n=1)$, salivary glands $(n=1)$, or thyroid gland $(n=1)$.

Our morphological and immunological findings were compatible with those of previous studies $^{917-2527}$ and will be published in a separate paper. The observation that monoclonality was evident only in plasma cells in two cases with pronounced plasmacytic differentiation, while monocytoid B cells did not express any immunoglobulin at all, is worth mentioning for its diagnostic implications.

We found that MBCL, like other low grade lymphomas, mainly affects the elderly. High rates of complete remission, relapse, and long term survival are common features. Our patients presented in all stages and had splenomegaly in seven cases. In one case of MBCL the tumour transformed into a centroblastic polymorphic lymphoma. Unlike other low grade lymphomas, bone marrow disease $(n=3)$ and leukaemic conversion $(n=1)$ were uncommon features of MBCL. ${ }^{2124252831}$ The clinical features of 21 patients with MBCL recently published by Sheibani et $a l^{23}$ agreed with our results on age distribution, rare bone marrow disease, rare development into a high grade lymphoma, treatment and high rates of complete remission and long term survival. They were at variance with our results regarding the distribution of primary disease, predominance of early stages of the disease, and low rates of splenomegaly and relapse. Clinically, four of Sheibani's patients with salivary gland disease had Sjögren's syndrome. One of our patients had an unclassified high grade lymphoma in bilateral salivary glands following a primary generalised MBCL, but no Sjögren's syndrome was documented. A history of Hashimoto's disease, an autoimmune disease which may also be considered a precursor to lymphoma, ${ }^{32}$ however, preceded a low grade B cell lymphoma in the thyroid diagnosed coincidentally with an MBCL in a regional lymph node.

According to the survival curve evaluated over a period of 83 months, the prognosis of MBCL was comparable with that of other low grade lymphomas. Additional extranodal components were found in three of the five patients who died and in five of the nine patients who relapsed. According to our results, however, patients in advanced stage MBCL had a worse prognosis and a higher risk of relapse than those in early stages. All three patients who died in spite of an early initial stage had a more complex history. Case 4, therefore, was not treated, because of myocardial infarction. Case 1 was lost to medical follow up and died in an unknown condition. Case 5 was not treated, because of an incorrectly diagnosed plasmacytoma in stage I; furthermore, this patient was most probably initially in a more advanced stage, according to the necropsy findings.

In seven patients with nodal MBCL a low grade B cell lymphoma of the MALT was found-in four of them this was in the stomach, in one in the nasopharynx, in one in the salivary glands and in one in the thyroid gland, which possibly belongs to the MALT. In two cases the tumour had developed into a high grade lymphoma. This coincidence merits more thorough discussion. Except for one case, MBCL was diagnosed in the corresponding regional lymph nodes so the question arises whether MBCL represents the equivalent in the lymph node of a low grade B cell lymphoma of the MALT. Morphological and immunological evidence may support this presumption when we compare these two lymphomas.

MBCL was characterised by its typical growth pattern of broad strands, by reactive looking germinal centres, and increased venules within the tumour infiltrates. Cytologically, the medium sized monocytoid B cells mainly showed irregularly shaped nuclei and a fairly broad rim of slightly basophilic cytoplasm. They all expressed $B$ cell antigens (positive reactions with $\mathrm{L} 26, \mathrm{Ki}-\mathrm{B} 3$, and $\mathrm{Ki}$ B5). In 14 cases monoclonal surface immunoglobulins were expressed, and five cases exhibited plasmacytic differentiation. One case of MBCL developed into a high grade lymphoma.

Low grade B cell lymphomas of the MALT, as described by Isaacson, ${ }^{14}$ show diffuse tumour invasion, lymphoid follicles, and lymphoepithelial lesions. Cytologically, the centrocyte-like tumour cells are small to intermediate in size, or of blastic appearance when the tumour has transformed into a high grade lymphoma. ${ }^{15}$ They exhibit monotypic immunoglobulin and other B cell antigens. Plasmacytic differentiation is reported in about $30 \%$ of all cases. 
Similarities were most prominent in three cases of mesenteric MBCL associated with a low grade B cell lymphoma of the MALT in the stomach, one of which developed into a high grade lymphoma. Nodal components were not distinguishable from regional metastasis (fig $2 a)$; additionally gastric components showed strands of monocytoid B cells that mimicked nodal MBCL to a varying degree. These strands of monocytoid B cells may have been described before, being interpreted as "clear cell" variants of centrocyte-like tumour cells. ${ }^{15}$ A striking resemblance between affected gastric lymph nodes and MBCL has been pointed out by us and other authors. ${ }^{153}$ Slight or more noticeable differences in pattern and in the cytological appearance of the tumour cells in nodal and extra-nodal sites seen in other cases may well be due to different micro-environments. More evidence in favour of one and the same process may be provided by immunological data based on our material. Thus in three of seven cases it was evident that the immunophenotypes of monocytoid B cells and centrocyte-like tumour cells were identical.

According to our clinical results, the manifestation of lymphoma in the MALT may be preceded by a fairly long period of lymphadenopathy, both localised and generalised. Thus in five patients extranodal lymphoma was found simultaneously, but in two of them only in a later phase of the disease. Our diagnosis of MBCL, though, always referred to an affected lymph node. Therefore, cases in which we found only extra-nodal lymphoma manifestation, with prominent strands of monocytoid B cells mimicking MBCL but without lymph node infiltration, were excluded from this study. This is at variance with Sheibani's interpretation of eight cases of exclusively extra-nodal disease affecting the salivary glands $(\mathbf{n}=3)$, the breast $(\mathbf{n}=2)$, the perigastric space with spread to the liver $(\mathrm{n}=1)$, the tonsil $(\mathrm{n}=1)$, and the retroperitoneal space $(\mathrm{n}=1)$. It is still a subject for discussion whether other tissues, such as the lung, lachrymal glands, tonsil, breast, and urinary genital tract may all belong to the MALT, but we think that the features reported in extra-nodal MBCL by Sheibani et $a l^{23}$ are consistent with a low grade $B$ cell lymphoma of the MALT.

We conclude that monocytoid B cell lymphoma of the lymph node is a very rare low grade lymphoma. It occurs fairly often in combination with a low grade B cell lymphoma of the MALT, most frequently localised in the stomach, indicating a close association between these two lymphomas. ${ }^{34}$ We emphatically urge clinicians to rule out an underlying low grade B cell lymphoma of the MALT in any case of nodal MBCL.

This work was supported by Schweizerischer Nationalfonds.

The authors most gratefully acknowledge devoted help for preparation of this manuscript by Mrs I Karlberg-Stannik and Mrs K Dege. We thank Mr W Vater, Mrs R Köpke, and Mrs H Blessmann for most skilful graphic and photographic assistance. Our thanks are also extended to all clinical colleagues for providing us with clinical data, as well as to Mrs Brütting for doing the necessary correspondence.

1 Lennert $K$. Diagnose and Atiologie der Piringer'schen Lymphadenitis. Verh Dtsch Ges Pathol 1959;42:203-8.

2 Stansfeld AG. The histological diagnosis of toxoplasmic

lymphadenitis. J Clin Pathol 1961;14:565-73.
3 van den Oord JJ, de Wolf-Peeters C, de Vos R, Desmet VJ. Immature sinus histiocytosis. Light- and electronmicroscopic features, immunologic phenotype, and microscopic features, immunologic phenotype, and relationship with

4 Stein H, Lennert K, Mason DY, Liangru S, Ziegler A. Immature sinus histiocytes. Their identification as a nove B-cell population. Am J Pathol 1984;117:44-52.

5 Sheibani K, Fritz RM, Winberg CD, Burke JS, Rappaport $H$. "Monocytoid" cells in reactive follicular hyperplasia with and without multifocal histiocytic reactions: An immunohistochemical study of 21 cases including suspected cases of toxoplasmic lymphadenitis. Am J Clin Pathol 1984;81:453-8.

6 de Almeida PC, Harris NL, Bahn AK. Characterisation of immature sinus histiocytes (monocytoid cells) in reactive ymph nodes by use of monoclonal antibodies. Hum Patho 1984;15:330-5.

7 Sohn CC, Sheibani K, Winberg CD, Rappaport H. Monocytoid $B$ lymphocytes: Their relation to the patterns of the aquired immunodeficiency syndrome (AIDS) and AIDSrelated lymphadenopathy. Hum Pathol 1985;16:979-85.

8 van den Oord JJ, de Wolf-Peeters C, Desmet VJ. Immature sinus histiocytosis in the lymphadenopathic stage of AIDS: Relationship to polyclonal B-cell activation? $J$ Pathol 1985;145:63-4.

9 Miettinen M, Franssila K. Malignant lymphoma simulating lymph node toxoplasmosis. Histopathol 1982;6:129-40.

10 Piris MA, Rivas C, Morente M, Oliva H, Rubio C. Immature sinus histiocytosis a monocytoid B-lymphoid eaction. J Pathol 1986;148:159-67.

11 Kumararatne DS, Bazin H, MacLennan ICM. Margina zones: The major B cell compartment of rat spleens. Eur J Immunol 1981;11:858-64.

12 MacLennan ICM, Gray D, Kumararatne DS, Bazin H. The lymphocytes of splenic marginal zones: A distinct B-cell lineage. Immunol Today 1982;3:305-7.

13 van den Oord JJ, de Wolf-Peeters C, Desmet VJ. The marginal zone in the human reactive lymph node. $\mathrm{Am} J$ marginal zone in the huma

14 Isaacson PG, Spencer J. Malignant lymphoma of mucosassociated lymphoid tissue. Histopathol 1987;11:445-62.

15 Myhre MJ, Isaacson PG. Primary B-cell gastric lymphoma-A reassessment of its histogenesis. J Patho 1987;152:1-11.

16 Van Krieken JHJM, Von Schilling C, Kluin M, Lennert K. Splenic marginal zone lymphocytes and related cells in the lymph node. A morphologic and immunohistochemical study. Hum Pathol 1989;20:320-5.

17 McGinn DL, Cousar JB, List AF, Glick AD, Collins RD. Report of an unusual interfollicular lymphoma arising from sinusoidal B lymphocytes. Lab Invest 1985;52:42A

18 Cousar JB, McGinn DL, Glick AD, Lis AF, Collins RD Report of an unusual lymphoma arising from parafollicular B-lymphocytes (PBLs) or so-called "monocytoid" lymphocytes. Am J Clin Pathol 1987;87:121-8.

19 Sheibani K, Sohn CC, Burke jS, Winberg CD, Wu AM, Rappaport H. Monocytoid B-cell lymphoma. A novel Bcell neoplasm. Am J Pathol 1986;124:310-8.

$20 \mathrm{Ng}$ CS, Chan JKC: Monocytoid B-cell lymphoma. Hum Pathol 1987;18:1069-71.

21 Agnarsson BA, Kadin ME. An unusual B-cell lymphoma simulating hairy cell leucemia. Am J Clin Pathol 1987;88:752-9.

22 Piris MA, Rivas C, Morente M, Cruz MA, Rubio C, Oliva H. Monocytoid B-cell lymphoma, a tumor related to the marginal zone. Histopathol 1988;12:383-92.

23 Sheibani K, Burke JS, Swartz WG, Nademanee A, Winberg CD. Monocytoid B-cell lymphoma. Clinicopathologic study of 21 cases of a unique type of low-grade-lymphoma. Cancer 1988;62:1531-8.

24 Traweek ST, Sheibani K, Winberg CD, Mena RR, Wu AM, Rappaport H. Monocytoid B-cell lymphoma: Its evolution and relationship to other low-grade-B-cell neoplasms. Blood 1989;73:573-8.

25 Carbone A, Gloghini A, Pinto A, Attadia V, Zagonel V, Volpe R. Monocytoid B-cell lymphoma with bone marrow and peripheral blood involvement at presentation. $A m \mathrm{~J}$ and peripheral blood involvem

26 Ngan BY, Takagi K, Dombrowski A, Dorfman RF. Monocytoid B-cell (Parafollicular B-cell) lymphoma: A study of 20 cases. Lab Invest 1989;60:66 A

27 Burke JS, Sheibani K. Hairy cells and monocytoid B ymphocytes: Are they related? Leukemia 1987;1:298-300.

28 Traweek ST, Sheibani K, Wu AM, Winberg CD, Rappaport $H$. Leucemic evolution of monocytoid B-cell lymphoma: Cvtochemical, immunologic and genotypic characterization of blood mononuclear and cultured cells. Leukemia 1988;2:197 A.

29 Mepham BL, Frater W, Mitchell BS. The use of proteolytic enzymes to improve immunoglobulin staining by the PAP technique. Histochem $J$ 1978;11:345-57.

30 Kaplan EL, Meier P. Non-parametric estimation from incomplete observations. J Am Statist Assoc 1958;53:45781.

31 Traweek ST, Weinberg CD, Sheibani K. Monocytoid B-cel lymphoma: Point on a spectrum. Am J Clin Pathol 988;90:748.

32 Lennert $\mathrm{K}$, Knecht $\mathrm{H}$, Burkest $\mathrm{M}$. Vorstadien maligner Lymphome (Prelymphomas). Verh Dtsch Ges Pathol 1979;63:170-96.

33 Tabrizchi H, Hansmann ML, Parwaresch MR, Lennert K. Distribution pattern of follicular dendritic cells in lowgrade B-cell lymphoma of the gastrointestinal tract immunostained by Ki-Blp, a new paraffin-resistant monoimmunostained by Ki-Blp, a new paraffin-resistant

34 Lennert K, Feller AC. Histopathologie der Non-HodgkinLymphome (nach der aktualisierten Kiei-Klassifikation) 